\title{
Gestão municipal do Programa Nacional de Alimentação Escolar nas capitais da região Sul do Brasil
}

\author{
Municipal management of the National \\ School Meal Program in the capitals \\ of Southern Brazil
}

Cristine Garcia GABRIEL ${ }^{1}$

Gabriela GOULART²

Maria Cristina Marino CALVO²

\section{R E S U M O}

\section{Objetivo}

Avaliar a gestão municipal do Programa de Alimentação Escolar nas três capitais da região Sul do Brasil.

\section{Métodos}

Pesquisa avaliativa por meio de estudo de casos múltiplos. O modelo contempla as dimensões político-organizacional (intersetorialidade da gestão) e técnico-operacional (responsabilidades da gestão específicas ao ambiente escolar). Foram coletados 22 indicadores por meio de entrevistas com os nutricionistas do programa.

\section{Resultados}

Dois casos foram classificados como regular e um como ruim. Destaque para Florianópolis, Santa Catarina, na gestão financeira e no estímulo ao desenvolvimento regional. Ênfase para Curitiba, Paraná, na qualificação profissional, no atendimento adequado às necessidades nutricionais específicas e na disponibilização de dados antropométricos. Porto Alegre, Rio Grande do Sul, destacou-se com a adequada equipe de produção de alimentos e a boa execução dos cardápios.

\footnotetext{
1 Universidade Federal de Santa Catarina, Centro de Ciências da Saúde, Programa de Pós-Graduação em Nutrição. Campus Universitário, Trindade, 88040-970, Florianópolis, SC, Brasil. Correspondência para/Correspondence to: MCM CALVO. E-mail:<mcmcalvo@ccs.ufsc.br>.

2 Universidade Federal de Santa Catarina, Centro de Ciências da Saúde, Programa de Pós-Graduação em Saúde Coletiva. Florianópolis, SC, Brasil.

Artigo elaborado a partir da tese de CG GABRIEL, intitulada "Programa Nacional de Alimentação Escolar: construção de modelo de avaliação da gestão municipal”. Universidade Federal de Santa Catarina; 2013.

Apoio: Conselho Nacional de Desenvolvimento Científico e Tecnológico (Processo no 475228/2010-3 e Edital MCT/CNPq no 014/2010 - Universal).
} 


\section{Conclusão}

Ainda que os resultados tenham sido menos satisfatórios do que o esperado, eles poderão estimular melhorias na gestão do programa ao dar ênfase à importância da avaliação como ferramenta legítima para qualificar os serviços.

Palavras-chave: Alimentação escolar. Avaliação de programas e projetos de saúde. Programas e políticas de nutrição e alimentação. Segurança alimentar e nutricional.

\section{A B S T R A C T}

\section{Objective}

To evaluate the municipal management of the Brazilian School Food Program in the three capitals of Southern Brazil.

\section{Methods}

This is an evaluative multiple-case study. The model addresses two dimensions of municipal management: the political-organizational dimension (inter-sector action) and the operational-technical dimension (responsibilities of management specific to the school environment). A total of 22 indicators were collected through interviews with program dietitians.

\section{Results}

Two cases were considered regular and one, bad. Florianópolis, Santa Catarina stands out in financial management and stimulus to regional development. Curitiba, Paraná stands out in the professional qualification, observance of specific nutritional needs, and availability of anthropometric data. Porto Alegre, Rio Grande do Sul stands out in the appropriateness of the food production team and good execution of the menus.

\section{Conclusion}

Although the results were less satisfactory than expected, they may encourage improvements in program management, emphasizing the importance of evaluation as a legitimate tool for service qualification.

Keywords: School feeding. Program evaluation. Nutrition programs and policies. Food and Nutrition security.

\section{N T R O D U Ç Ã O}

Com caráter suplementar, o Programa Nacional da Alimentação Escolar (PNAE) visa a suprir as necessidades nutricionais dos alunos da rede pública brasileira durante o tempo de permanência no ambiente escolar, com a proposta de contribuir com o crescimento, o desenvolvimento, a aprendizagem, o rendimento escolar e a formação de hábitos alimentares saudáveis'

Desde a descentralização, o programa passou por constantes aprimoramentos, como a criação dos Conselhos de Alimentação Escolar $(\mathrm{CAE})$, a vinculação do nutricionista à responsabilidade técnica e o incentivo à compra da agricultura familiar ${ }^{1,2}$. Em âmbito municipal, a gestão do PNAE é de responsabilidade da Secretaria Municipal de Educação, que pode gerir o programa de distintas formas ${ }^{2}$. Nesse quesito, estudos avaliativos buscaram investigar se a execução do programa acompanhava a sua evolução normativa, revelando dificuldades e inadequações em distintos aspectos. Em 2008, apenas $22 \%$ dos CAE do estado de Santa Catarina realizavam suas atribuições com frequência maior que anual $^{3}$. Entre os anos de 2003 e 2011, o percentual de municípios brasileiros com nutricionistas cadastrados no Fundo Nacional de Desenvolvimento da Educação/Ministério da Educação (FNDE/MEC) cresceu de 12 para 79\%. Apesar da importante evolução, 21\% dos municípios ainda não eram assistidos pelo profissional ${ }^{4}$. Em 2010, apenas $47 \%$ dos municípios brasileiros compravam alimentos da agricultura familiar, e o percentual médio de aquisição $(23 \%)^{5}$ ainda se encontrava abaixo do exigido $(30 \%)^{2}$.

Visando contemplar as múltiplas faces do PNAE, diferentes autores têm se dedicado a 
desenvolver metodologias voltadas a avaliações mais abrangentes do Programa ${ }^{6-8}$. Dentre estas, foi elaborado em 2012 um modelo para avaliação da gestão municipal do PNAE, com foco nas escolas de ensino fundamental ${ }^{9}$. Essa proposta, considerada pertinente ${ }^{9}$, foi testada nos dez maiores municípios de Santa Catarina com mais de cem mil habitantes, tendo sido também aplicada nas três capitais do Sul do Brasil. Ainda que o PNAE tenha sido previamente avaliado nessas capitais em determinados aspectos ${ }^{3-5,10-12}$, não foram encontradas publicações acerca da gestão municipal do Programa.

Este artigo apresenta e discute os resultados encontrados nessa avaliação, e busca evidenciar especificidades entre as capitais que possam contribuir para a qualificação da gestão municipal do PNAE. Espera-se também colaborar para o aprimoramento e a institucionalização de processos avaliativos no PNAE.

\section{M É T O D O S}

Os dados deste artigo são parte de uma pesquisa de maior extensão (Processo $n^{\circ} 475228$ / 2010-3), realizada entre os anos de 2011 e 2013, com gestores da alimentação escolar das três capitais do Sul do Brasil - Florianópolis (SC), Porto Alegre (RS) e Curitiba (PR). Detalhes do desenho e desenvolvimento metodológico da investigação foram descritos anteriormente ${ }^{9,13}$.

Trata-se de pesquisa avaliativa, por meio de estudo de casos múltiplos, com a aplicação de um modelo direcionado às ações da gestão municipal do PNAE, com foco no ensino fundamental, nas capitais da região Sul do Brasil.

Com notáveis diferenças demográficas, as capitais atendem a um número de escolas e de escolares distintos. No entanto, apesar de demonstrarem três formas variadas de gestão do PNAE, possuem um contexto socioeconômico semelhante, com bons níveis de desenvolvimento humano e expectativa de vida (Quadro 1).

Quadro 1. Características dos casos avaliados na gestão municipal do Programa Nacional de Alimentação Escolar (PNAE). Florianópolis (SC), Curitiba (PR) e Porto Alegre (RS), 2011.

\begin{tabular}{|c|c|c|c|}
\hline Características & Florianópolis & Curitiba & Porto Alegre \\
\hline Área $\left(\mathrm{km}^{2}\right)^{*}$ & 675,4 & 435,0 & 496,6 \\
\hline População* & 421240 & 1751907 & 1409351 \\
\hline $\mathrm{IDHM}^{* *}$ & 0,681 & 0,640 & 0,66 \\
\hline Expectativa de vida** & 71,25 anos & 68,7 anos & 69,87 anos \\
\hline IDEB $5^{\circ}$ ano ${ }^{* * *}$ & 6,0 & 5,8 & 4,4 \\
\hline IDEB $8^{\circ} \mathrm{ano}^{* * *}$ & 4,6 & 4,7 & 3,6 \\
\hline $\begin{array}{l}\text { Número de escolares no } \\
\text { ensino fundamental }\end{array}$ & 15325 & 94484 & 36624 \\
\hline $\begin{array}{l}\text { Número de escolas com } \\
\text { ensino fundamental }{ }^{\&}\end{array}$ & 37 & 184 & 54 \\
\hline Gestão do PNAE & $\begin{array}{l}\text { Centralizada com terceirização da } \\
\text { mão de obra desde } 1998\end{array}$ & Terceirizada desde 1998 & $\begin{array}{l}\text { Centralizada com cozinheiros e } \\
\text { auxiliares gerenciados por coopera- } \\
\text { tiva trabalhista }\end{array}$ \\
\hline Profissionais de nutrição & $\begin{array}{l}\text { Concursadas: } 1 \\
\text { (40h/semanais), } 2 \\
\text { (30h/semanais). } \\
\text { Terceirizadas: quantitativo não dis- } \\
\text { ponibilizado }\end{array}$ & $\begin{array}{l}\text { Concursadas: } 5 \\
\text { (40h/semanais) } \\
\text { Terceirizadas: } 16 \\
\text { (44h/semanais) }\end{array}$ & $\begin{array}{l}\text { Concursadas: } 9 \\
\text { (40h/semanais), } 1 \\
\text { (30h/semanais) } \\
\text { Uma estagiária ou técnica de nutri- } \\
\text { ção por escola ( } 20 \text { a 30h/semanais) }\end{array}$ \\
\hline
\end{tabular}

Nota: *Cidades@, Instituto Brasileiro de Geografia e Estatística, 2010 (http://cidades.ibge.gov.br/xtras/home.php?lang); ${ }^{* *}$ Atlas do Desenvolvimento Humano, Pesquisa Nacional de Unidade Domiciliar (PNUD)/Instituto de Pesquisa, Estatística e Análise (IPEA), 2013; ${ }^{* * *}$ Instituto Nacional de Estatística e Pesquisa (INEP), 2011 (http://ideb.inep.gov.br/resultado/home.seam?cid=1954005); †'Matrículas no ensino fundamental - INEP, 2011 (http://portal.inep.gov.br/basica-censo-escolar-matricula). "Número de escolas municipais de ensino fundamental. "DataEscola", INEP, 2013 (http://www.dataescolabrasil.inep.gov.br/dataEscolaBrasil/).

IDHM: Índice de Desenvolvimento Humano Municipal; IDEB: Índice de Desenvolvimento da Educação Básica. 
A estrutura do modelo contempla duas dimensões da gestão municipal do PNAE: dimensão político-organizacional e técnico-operacional. A dimensão político-organizacional refere-se à intersetorialidade da gestão, considerando-se desde as ações de planejamento até a avaliação e monitoramento das ações desenvolvidas. A dimensão técnico-operacional contempla as responsabilidades da gestão específicas ao ambiente escolar, relacionadas à realização do direito à alimentação escolar adequada9 ${ }^{9}$. As duas dimensões foram subdivididas em três subdimensões cada uma, avaliadas por 22 indicadores e 45 medidas $^{9}$ (Quadros 2 e 3).

Os 22 indicadores apresentam de 1 a 5 medidas, em alguns casos em formato de check-list. As medidas possuem o mesmo peso dentro do indicador, e os indicadores foram considerados equivalentes entre $\mathrm{si}^{9,13}$. Para a avaliação dos indicadores, foram consideradas as seguintes regras:

- Indicador com 1 medida: a classificação do indicador é a mesma da medida;

- Indicador com 2 medidas: "bom" com $50 \%$ de bom sem nenhum ruim, "ruim" com

Quadro 2. Subdimensões, indicadores e medidas da dimensão político-organizacional do modelo avaliativo da gestão municipal do Programa Nacional de Alimentação Escolar (PNAE).

\begin{tabular}{|c|c|c|}
\hline Sub & Indicador & Medidas \\
\hline \multirow{8}{*}{ 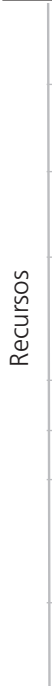 } & $\begin{array}{l}\text { 1. Participação da entidade executora } \\
\text { na execução financeira do PNAE }\end{array}$ & $\begin{array}{l}\text { - Relação de investimento em alimentos Secretaria Municipal de Educação/FNDE } \\
\text { - Utilização do recurso federal (saldo anual) }\end{array}$ \\
\hline & $\begin{array}{l}\text { 2. Adequação do quadro de nutricionis- } \\
\text { tas }\end{array}$ & - Relação nutricionista/escolar \\
\hline & $\begin{array}{l}\text { 3. Adequação da equipe de produção } \\
\text { das refeições }\end{array}$ & $\begin{array}{l}\text { - Relação refeições/manipuladores de alimentos } \\
\text { - Execução pelos manipuladores de atribuições extras ao PNAE }\end{array}$ \\
\hline & 4. Qualificação do profissional & $\begin{array}{l}\text { - Existência na Secretaria Municipal de Educação de programa de formação intro- } \\
\text { dutório para novos manipuladores } \\
\text { - Quantitativo de manipuladores formados nos últimos dois anos }\end{array}$ \\
\hline & 5. Condições para o trabalhador & Check list* \\
\hline & 6. Condições para o trabalho & Check list ${ }^{*}$ \\
\hline & $\begin{array}{l}\text { 7. Condições adequadas para o ar- } \\
\text { mazenamento e preparo dos alimen- } \\
\text { tos }\end{array}$ & $\begin{array}{l}\text { - Existência de "Manual de boas práticas, procedimentos operacionais padroniza- } \\
\text { dos" e "Fichas técnicas das preparações" nas escolas }\end{array}$ \\
\hline & 8. Local adequado para as refeições & $\begin{array}{l}\text { - Quantitativo de escolas com refeitórios em condições adequadas para receber os } \\
\text { alunos }\end{array}$ \\
\hline \multirow{3}{*}{ 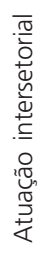 } & $\begin{array}{l}\text { 1. Articulação do PNAE com o setor } \\
\text { saúde }\end{array}$ & $\begin{array}{l}\text { - Existência de projeto/programa realizado pela gestão do PNAE em conjunto com a } \\
\text { Secretaria Municipal de Educação }\end{array}$ \\
\hline & $\begin{array}{l}\text { 2. Relação escolas - Unidades Básicas } \\
\text { de Saúde }\end{array}$ & $\begin{array}{l}\text { - Existência de rotina de encaminhamento de escolares diagnosticados na escola em } \\
\text { risco nutricional para Unidades Básicas de Saúde }\end{array}$ \\
\hline & $\begin{array}{l}\text { 3. Estímulo ao desenvolvimento re- } \\
\text { gional }\end{array}$ & $\begin{array}{l}\text { - Utilização do recurso federal com a agricultura familiar } \\
\text { - Realização de ações que incentivaram a entrada de produtores regionais no PNAE }\end{array}$ \\
\hline \multirow{3}{*}{ 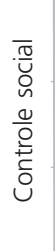 } & $\begin{array}{l}\text { 1. Regularidade da atuação do contro- } \\
\text { le social }\end{array}$ & - Número de reuniões com quórum mínimo realizadas pelo CAE com registro em ata \\
\hline & 2. Perfil da atuação do CAE & $\begin{array}{l}\text { - Check list* sobre os itens registrados nas atas das reuniões do CAE } \\
\text { - Check list* sobre o perfil deliberativo do CAE }\end{array}$ \\
\hline & $\begin{array}{l}\text { 3. Apoio institucional ao controle so- } \\
\text { cial }\end{array}$ & - Check list ${ }^{*}$ com os itens disponibilizados aos conselheiros \\
\hline
\end{tabular}

Nota: *Disponíveis na tese de doutorado "Programa Nacional de Alimentação Escolar: construção de modelo de avaliação da gestão municipal", 2013. https://repositorio.ufsc.br/handle/123456789/106997.

FNDE: Fundo Nacional de Desenvolvimento da Educação; CAE: Conselhos de Alimentação Escolar; Sub: Subdimensão. 
Quadro 3. Subdimensões, indicadores e medidas da dimensão técnico-operacional do modelo avaliativo da gestão municipal do Programa Nacional de Alimentação Escolar (PNAE).

\begin{tabular}{|c|c|c|}
\hline Sub & Indicador & Medidas \\
\hline \multirow{4}{*}{ 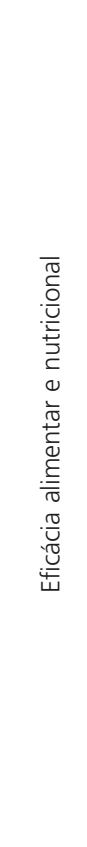 } & 1. Adequação da oferta & $\begin{array}{l}\text { - Orientação padronizada sobre o porcionamento a cada mudança de cardápio } \\
\text { - Inclusão diária de frutas ou hortaliças nos cardápios } \\
\text { - Frequência mensal de alimentos que devem ser controlados no cardápio (sal- } \\
\text { sicha/linguiça; margarina; achocolatado e pudim/creme doce) } \\
\text { - Realização de cálculo dos valores nutricionais dos cardápios planejados } \\
\text { - Realização de orientações para os alimentos comercializados nas cantinas }\end{array}$ \\
\hline & 2. Respeito à cultura alimentar saudável & $\begin{array}{l}\text { - Inserção de alimentos/preparações locais/regionais nos cardápios } \\
\text { - Atendimento diferenciado e adequado para povos e comunidades tradicio- } \\
\text { nais (indígenas e quilombolas) } \\
\text { - Realização de investigação sobre os hábitos alimentares dos escolares }\end{array}$ \\
\hline & 3. Execução do cardápio & $\begin{array}{l}\text { - Existência de sistema de controle sobre as substituições de cardápios realiza- } \\
\text { das nas escolas } \\
\text { - Prejuízo do equilíbrio nutricional com as substituições de cardápios } \\
\text { - Problema com licitação que prejudicou o cumprimento de um cardápio ade- } \\
\text { quado } \\
\text { - Existência de sistema de controle sobre o número de refeições/dia/escola }\end{array}$ \\
\hline & $\begin{array}{l}\text { 4. Adequação dos cardápios para escolares } \\
\text { que necessitam de atenção específica }\end{array}$ & $\begin{array}{l}\text { - Existência de cardápios adequados para atender cada grupo de escolares com } \\
\text { necessidades nutricionais especiais }\end{array}$ \\
\hline \multirow{2}{*}{ 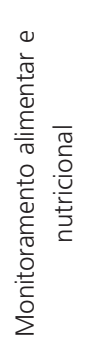 } & 1. Vigilância nutricional dos escolares & $\begin{array}{l}\text { - Existência de dados de avaliação do estado nutricional dos escolares com } \\
\text { periodicidade no mínimo anual } \\
\text { - Cobertura de escolares avaliados (peso e altura) } \\
\text { - Utilização das informações de avaliação nutricional no planejamento do PNAE }\end{array}$ \\
\hline & 2. Supervisão do nutricionista & $\begin{array}{l}\text { - Periodicidade mensal das visitas por escola sob responsabilidade da equipe } \\
\text { técnica de nutrição } \\
\text { - Periodicidade mensal do acompanhamento do porcionamento das refeições } \\
\text { nas escolas, sob responsabilidade da equipe técnica de nutrição }\end{array}$ \\
\hline \multirow{2}{*}{ 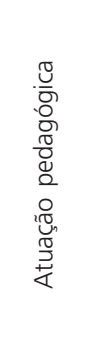 } & $\begin{array}{l}\text { 1. Ações de estímulo à educação alimentar } \\
\text { e nutricional }\end{array}$ & $\begin{array}{l}\text { - Existência de projetos e/ou atividades educativas abrangentes, estimulados } \\
\text { pela Secretaria Municipal de Educação na área de alimentação escolar e } \\
\text { direcionados aos escolares } \\
\text { - Quantitativo de escolas que desenvolvem atividades práticas regulares de in- } \\
\text { centivo à alimentação saudável }\end{array}$ \\
\hline & $\begin{array}{l}\text { 2. Transversalidade do tema alimentação } \\
\text { saudável }\end{array}$ & $\begin{array}{l}\text { - Inserção do tema alimentação saudável no currículo } \\
\text { - Capacitação de professores para trabalhar o tema alimentação saudável no } \\
\text { currículo }\end{array}$ \\
\hline
\end{tabular}

Nota: Sub: Subdimensão.

$50 \%$ de ruim sem nenhum bom, "regular" nas demais situações;

- Indicador com 3 ou mais medidas: "bom" com $50 \%$ de bom sem nenhum ruim, "ruim" com mais que $50 \%$ de ruim nas medidas, "regular" nas demais situações ${ }^{9,13}$.
Nos casos em que a medida era no formato de check list, os itens componentes eram todos binários, com respostas "sim" ou "não". Cada check list foi avaliado como bom quando possuía 75\% das respostas positivas ou mais, e ruim quando abaixo desse valor. A inexistência 
ou o não fornecimento de dados foi considerado resposta negativa. O juízo de valor e os escores de classificação para cada subdimensão e dimensão foram descritos anteriomente ${ }^{9,13}$.

Os nutricionistas responsáveis técnicos foram indicados pelos gestores para serem os informantes-chave. Entre abril e agosto de 2012, foram realizadas visitas para entrevista estruturada com os respondentes e coleta dos dados documentais referentes ao ano anterior de execução do PNAE (2011). As entrevistas foram gravadas e transcritas.

Os resultados são apresentados por meio de classificação em relação aos indicadores investigados e análise descritiva dos dados.

A pesquisa foi aprovada pelo Comitê de Ética em Pesquisa da Universidade Federal de Santa Catarina (Processo n 1143/2010). Os participantes assinaram um Termo de Consentimento Livre e Esclarecido.

\section{RES U LT A DOS}

Observando-se os indicadores investigados (Figura 1), dois dos três casos foram classificados como regulares, com seis indicadores bons e oito regulares, enquanto um caso classificou-se como ruim, com quatro indicadores positivos e seis regulares.

\section{Dimensão político-organizacional}

Na subdimensão "Recursos", a contrapartida das três capitais, comparada ao investimento federal, variou entre 49 e $328 \%$. A utilização do recurso federal em 2011 gerou saldos de 2, 28 e $53 \%$. Saldos superiores a $20 \%$ foram considerados ruins. As três capitais demonstraram inadequação no quadro de nutricionistas ${ }^{2}$. Vale destacar uma estratégia utilizada por uma das capitais que, além dos nutricionistas, contava com técnicos de nutrição concursados e estagiários em nutrição, que faziam a supervisão nas unidades escolares diariamente (20 horas semanais/uni- dade). Apenas uma das capitais disponibilizou dados sobre a equipe de manipuladores de alimentos, que foi avaliada positivamente com uma média de 109 refeições/manipulador/dia. As três capitais formavam os manipuladores periodicamente, porém em apenas uma eram realizados cursos de formação introdutória. O salário dos nutricionistas era desigual entre contratados e concursados em duas das capitais, sendo que em apenas uma delas o valor observado estava acima do piso de referência para todos os nutricionis$\operatorname{tas}^{14}$. Nenhuma capital fornecia plano de carreira aos manipuladores de alimentos, que eram, em sua grande maioria, terceirizados. Somente uma das capitais fornecia sala de trabalho, equipamentos de avaliação nutricional e locomoção adequados para os nutricionistas. Foi observada a disponibilização de softwares computacionais para atividades técnicas, porém eles nem sempre foram avaliados positivamente pelo nutricionista. As capitais não forneciam uniformes e equipamentos de proteção individual em quantidade e qualidade adequada a todos os funcionários. Apesar de todas as escolas possuírem "Manual de boas práticas e procedimentos operacionais padronizados", nenhuma apresentava "Fichas técnicas de preparação" concluídas. Com exceção de uma das capitais, a qualificação dos refeitórios foi positiva.

Na subdimensão "Atuação intersetorial", os três municípios relataram articulação do PNAE com o setor saúde em algum nível. Os três casos apresentaram iniciativas incipientes em relação ao Programa Saúde na Escola. Destaca-se que uma das capitais utilizava o Sistema de Vigilância Alimentar e Nutricional (Sisvan) do escolar desde 1996, sendo que os dados antropométricos dos alunos eram obtidos anualmente sob a coordenação de nutricionistas dos setores da Educação e Saúde. Foram relatadas, ainda, iniciativas em construção de ações de incentivo à amamentação em creches. Nenhuma das capitais possuía rotina de encaminhamento de escolares para unidades de saúde. A compra da agricultura familiar era realizada por todos os casos, porém apenas um 


\begin{tabular}{|c|c|c|c|c|c|}
\hline Subdimensão & Indicadores & M1 & M2 & M3 & $\begin{array}{l}\text { n municípios que } \\
\text { atingiram "bom" }\end{array}$ \\
\hline \multirow{8}{*}{ Recursos } & $\begin{array}{l}\text { 1. Participação da entidade executora na execução finan- } \\
\text { ceira do PNAE }\end{array}$ & & & & 1 \\
\hline & 2. Adequação do quadro de nutricionistas & & & & 0 \\
\hline & 3. Adequação da equipe de produção das refeições & & & & 1 \\
\hline & 4. Qualificação do profissional & & & & 1 \\
\hline & 5. Condições para o trabalhador & & & & 0 \\
\hline & 6. Condição para o trabalho & & & & 0 \\
\hline & $\begin{array}{l}\text { 7. Condições adequadas para o armazenamento e prepa- } \\
\text { ro dos alimentos }\end{array}$ & & & & 0 \\
\hline & 8. Local adequado para as refeições & & & & 2 \\
\hline \multirow{3}{*}{ Atuação intersetorial } & 9. Articulação do PNAE com o setor saúde & & & & 2 \\
\hline & 10. Relação escolas - Unidades Básicas de Saúde & & & & 0 \\
\hline & $\begin{array}{l}\text { 11. Estímulo ao desenvolvimento regional para a produ- } \\
\text { ção de alimentos }\end{array}$ & & & & 1 \\
\hline \multirow{3}{*}{ Controle social } & 12. Regularidade da atuação do controle social & & & & 1 \\
\hline & 13. Perfil da atuação do CAE & & & & 0 \\
\hline & 14. Apoio institucional ao controle social & & & & 2 \\
\hline \multirow{4}{*}{$\begin{array}{l}\text { Eficácia alimentar e } \\
\text { nutricional }\end{array}$} & 15. Adequação da oferta & & & & 0 \\
\hline & 16. Respeito à cultura alimentar saudável & & & & 0 \\
\hline & 17. Execução do cardápio & & & & 1 \\
\hline & $\begin{array}{l}\text { 18. Adequação dos cardápios para escolares que neces- } \\
\text { sitam de atenção específica }\end{array}$ & & & & 1 \\
\hline \multirow{2}{*}{$\begin{array}{l}\text { Monitoramento alimentar e } \\
\text { nutricional }\end{array}$} & 19. Vigilância nutricional dos escolares & & & & 1 \\
\hline & 20. Supervisão do nutricionista & & & & 0 \\
\hline \multirow{2}{*}{ Atuação pedagógica } & 21. Ações de estímulo à educação alimentar e nutricional & & & & 0 \\
\hline & 22. Transversalidade do tema alimentação saudável & & & & 2 \\
\hline \multirow{2}{*}{$\begin{array}{l}\text { Total de "bom" por } \\
\text { município }\end{array}$} & $n$ & 6 & 6 & 4 & \\
\hline & $\%$ & $27 \%$ & $27 \%$ & $18 \%$ & \\
\hline
\end{tabular}

Figura 1. Resultados da avaliação da gestão municipal do Programa Nacional de Alimentação Escolar (PNAE) segundo indicadores, por municípios. Florianópolis (SC), Curitiba (PR) e Porto Alegre (RS), 2011.

Nota: CAE: Conselhos de Alimentação Escolar; M1: Florianópolis; M2: Curitiba; M3: Porto Alegre.

empregou o mínimo de $30 \%^{2}$ dos recursos repassados pelo FNDE em 2011 nessa modalidade. Todos os casos referiram ações para apoiar a entrada e a permanência do pequeno produtor no PNAE.
A subdimensão "Controle social" trata da regularidade da atuação dos CAE. Neste estudo, considerou-se como adequada a realização de dez ou mais reuniões anuais, sendo que apenas uma capital alcançou essa frequência. No "Perfil de 
atuação do CAE", observaram-se poucas visitas a unidades escolares por parte das três capitais, não alcançando a média de ao menos uma visita mensal em 2011. Uma das capitais destacou-se na discussão de temas de importância para o PNAE durante as reuniões do CAE, ainda que não fossem registradas deliberações sobre ações do programa. Em geral, eram fornecidos equipamentos de informática e recursos humanos para as atividades do CAE.

A classificação geral nessa dimensão resultou em dois casos regulares e um ruim.

\section{Dimensão técnico-operacional}

Na subdimensão "Eficácia alimentar e nutricional", observou-se a ausência de orientações periódicas sobre o porcionamento das refeições nos três municípios. Duas das três capitais ofereciam frutas ou hortaliças diariamente, e a frequência de qualquer item controlado (salsicha/linguiça, margarina, achocolatado e pudim/ creme doce) mostrou-se inferior a quatro vezes/ mês nos cardápios. Somente uma capital realizava o cálculo dos valores nutricionais dos cardápios, considerando apenas os macronutrientes. Alimentos típicos regionais eram ofertados com frequência semanal e mensal, porém observou-se pouca variedade na oferta em uma das capitais. Observou-se que a presença diária de estagiário ou técnico de nutrição nas escolas de uma capital servia também como mecanismo de controle sobre as substituições realizadas nos cardápios. Outras formas relatadas foram o controle indireto, que limita a disponibilização dos alimentos em estoque, e a vinculação das trocas à permissão do nutricionista. Nenhum caso relatou problema ou atraso com as licitações que prejudicasse o cumprimento dos cardápios. Os três municípios atendiam às necessidades nutricionais específicas dos escolares com cardápios variados, porém observou-se que apenas um deles atendia a todas as necessidades identificadas.

Na subdimensão "Monitoramento alimentar e nutricional", destaca-se a iniciativa do
Sisvan escolar em uma capital que disponibilizava dados anuais de avaliação nutricional de todos os estudantes desde 1996. Apesar disso, esses dados ainda eram utilizados apenas para ações pontuais devido à insuficiência de recursos humanos que os avaliassem adequadamente. Observou-se também a existência de dados parciais coletados pelo Programa Saúde na Escola e por parcerias com universidades, entretanto não estavam sistematizados na época da pesquisa e não eram utilizados no PNAE. No indicador sobre a supervisão do nutricionista nas escolas, ressalta-se a presença constante do estagiário ou técnico de nutrição em um dos três casos. Em geral, os nutricionistas realizavam visitas escolares com frequência entre semanal e mensal. Os nutricionistas terceirizados possuíam frequencia pré-estabelecida para as visitas.

Na subdimensão "Atuação pedagógica para a alimentação saudável", apenas uma capital relatou a existência de projetos educativos que envolvessem toda a rede. O tema alimentação saudável foi observado no currículo escolar de duas capitais, porém essa inserção foi considerada incipiente e desatualizada, não sendo incorporada como rede. Uma das capitais realizou ainda capacitação de parte dos professores em educação alimentar e nutricional, entretanto com metodologia ainda pendente de monitoramento e avaliação. Os resultados desses indicadores refletiram na classificação dessa dimensão, que resultou em dois casos regulares e um ruim.

A partir dos resultados das duas dimensões, dois municípios receberam classificação regular e um ruim (Figura 2).

\section{I S C U S S Ã O}

As três capitais foram mais bem avaliadas do que grande parte dos dez maiores municípios de Santa Catarina observados sob o mesmo modelo avaliativo em $2012^{13}$. No estudo catarinense, a dimensão político-organizacional resultou em $60 \%$ dos casos regulares e $40 \%$ ruins, e a dimensão técnico-operacional obteve $90 \%$ dos casos 


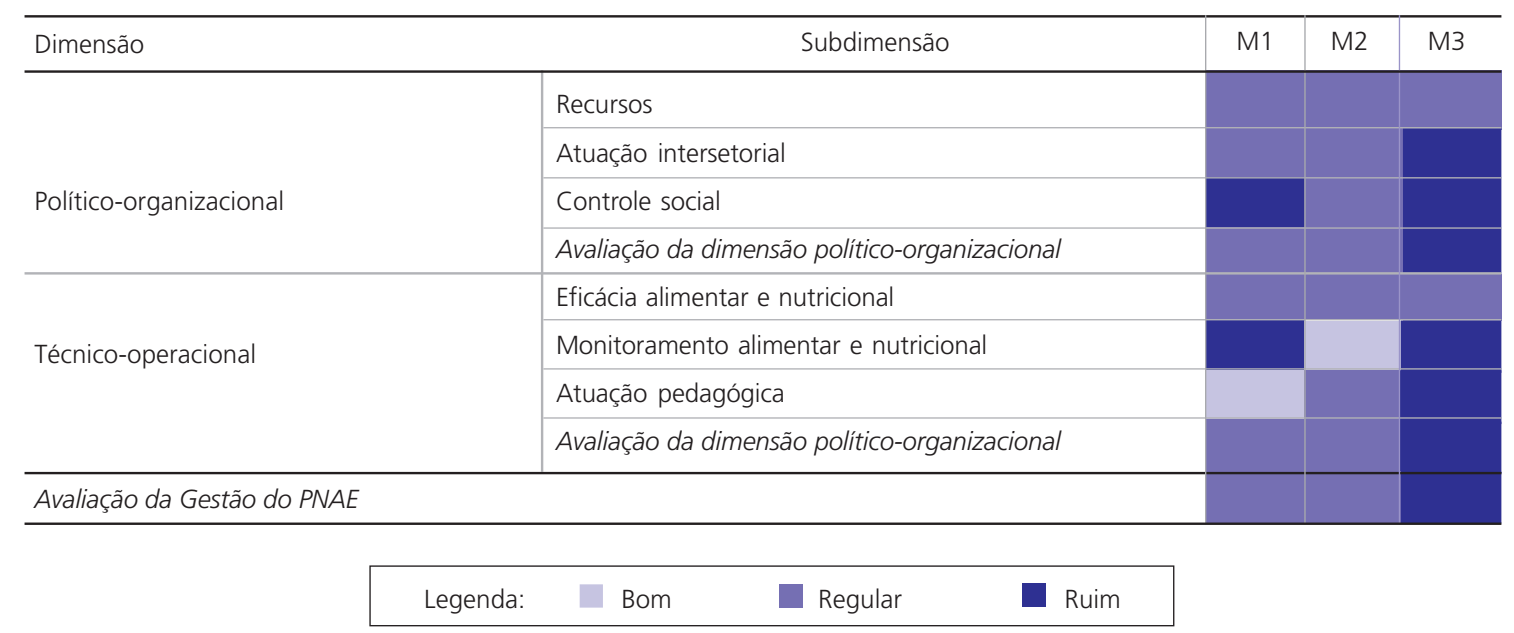

Figura 2. Resultados da avaliação da gestão municipal do Programa Nacional de Alimentação Escolar (PNAE) segundo subdimensão, dimensão e gestão municipal. Florianópolis (SC), Curitiba (PR) e Porto Alegre (RS), 2011.

Nota: M1: Florianópolis; M2: Curitiba; M3: Porto Alegre.

ruins, consequência do baixo desempenho no monitoramento e na atuação pedagógica. Esses dados refletiram na avaliação final dos municípios, que apontou $90 \%$ dos casos como ruins ${ }^{13}$. Na presente avaliação, dois casos foram classificados como regular e um como ruim. Apesar de esses resultados mostrarem-se melhores quando comparados aos casos catarinenses, a classificação geral ficou aquém do que seria um resultado ideal, já que nenhuma capital obteve classificação máxima.

Na subdimensão "Recursos", a contrapartida das três capitais foi considerada alta, assim como a observada entre os municípios participantes do Prêmio Gestor Eficiente da Merenda, em 2004 e $2005^{10}$. Já o recurso federal destinado aos municípios é calculado per capita. Assim, a máxima utilização dos recursos, com saldo anual o menor possível, pode ser sugestiva de conhecimento por parte da gestão sobre as necessidades financeiras do programa. Florianópolis destacou-se no gerenciamento adequado dos recursos do PNAE, com o menor saldo anual e a maior contrapartida. As três capitais apresentaram déficit de nutricionistas, problema constatado também em outras cidades brasileiras ${ }^{4,10,11}$. O nutricionista tem papel de importância crescente dentro do programa ${ }^{15}$, e algumas das suas atri- buições ${ }^{2,4}$ podem estar prejudicadas com o quadro apresentado. Sobre a equipe de manipuladores de alimentos, depara-se ainda com a ausência de parâmetros específicos para o PNAE. Apesar disso, destaca-se que Porto Alegre foi a única capital que possuía controle sobre a capacidade de produção dos manipuladores e apresentou média de refeições/manipulador/dia melhor do que aquelas encontradas em outros municípios $^{10,13}$. Porto Alegre destacou-se como a capital com melhor salário base fornecido aos nutricionistas. Outros autores já relataram que o nutricionista que trabalha no PNAE encontra-se em desvantagem salarial em relação a outras áreas da nutrição ${ }^{15}$. A Consolidação das Leis do Trabalho' ${ }^{16}$ não determina obrigatoriedade em conceder todos os direitos investigados neste estudo, porém, ao se preservarem esses direitos, melhoram-se as condições de trabalho e, consequentemente, a execução do $\mathrm{PNAE}^{10}$. Assim como três dos dez municípios investigados em Santa Catarina em $2012^{13}$, Porto Alegre não controlava a frequência de realização dos exames médicos exigidos aos manipuladores de alimentos. Sabendo-se da relação intrínseca entre os manipuladores e a veiculação de patógenos, o controle da saúde do trabalhador torna-se essencial ${ }^{17}$. Chama a atenção o fato de que duas das três capitais não realizavam formações introdutórias para manipuladores. A 
capacitação nesse momento pode ser crucial para manter a padronização e garantir a qualidade do serviço ${ }^{17}$.

Na subdimensão "Atuação intersetorial", destaca-se Curitiba pela utilização do Sisvan do escolar desde 1996. Além da distribuição de responsabilidades entre os setores, trabalhos conjuntos auxiliam na identificação das necessidades de saúde do escolar, facilitando o monitoramento de suas condições. Ressalta-se a importância da compra da agricultura familiar para o PNAE, com destaque para Florianópolis, que atingiu o percentual mínimo de compra em 2011. Cardápios com gêneros fornecidos por produtores locais fortalecem a economia da região e tendem a apresentar melhor qualidade nutricional 1,2,5,18.

Na subdimensão "Controle social", a atuação do CAE deve ocorrer por meio do acompanhamento e reflexão acerca das ações desenvolvidas no PNAE. A realidade observada nas capitais preocupa: apenas Porto Alegre alcançou a frequência adequada de reuniões do $C A E$, embora fornecesse pouco suporte ao conselho. Foram observadas poucas visitas às escolas e pouco debate acerca de temas de importância para o PNAE, o que refletiu negativamente sobre a influência prática dos conselhos na melhoria do programa. Diferente dessa situação, os CAE de alguns municípios brasileiros, em 2009, tiveram participação determinante na contratação de nutricionistas e no impedimento de mudanças de gestão ${ }^{10}$.

Na subdimensão "Eficácia alimentar e nutricional", um dado preocupante foi que a única capital que realizava o cálculo dos cardápios foi Porto Alegre, ainda assim apenas para os macronutrientes. Apesar disso, assim como as outras duas capitais, não orientava sobre o porcionamento, essencial para monitorar minimamente a quantidade consumida pelos estudantes e evitar desperdícios $^{19}$. Na região Nordeste, em 2007, a maioria das nutricionistas relatou calcular os cardápios $^{15}$, ação fundamental ao se considerar o tempo despendido pelos escolares na escola, que acaba fornecendo um terço ou mais de suas refeições. O planejamento do cardápio pelo nutricionista ${ }^{1,2,4}$ deve considerar os aportes de nutrientes recomendados ${ }^{2}$ e as condições fisiológicas e antropométricas dos escolares ${ }^{6}$ e figura como etapa essencial à efetivação dos objetivos do PNAE ${ }^{6,11}$. Todas as capitais destacaram-se por controlar a situação das cantinas ou por sua ausência. Nas escolas onde há cantinas, esta é a primeira opção das crianças que não consomem a alimentação escolar ${ }^{20}$, ressaltando a importância de regulamentar esse serviço. Em 2001, Florianópolis foi a pioneira no Brasil a estabelecer uma legislação direcionada ao controle dos alimentos comercializados nas cantinas ${ }^{21}$. Iniciativas similares apareceram em todo o território nacional, incluindo Paraná, em 200422, e Porto Alegre, em $2007^{21}$. Vale destacar a presença diária de um estagiário ou técnico em nutrição nas escolas de Porto Alegre, fato que influenciou positivamente as ações de controle de qualidade e execução do cardápio. Esse resultado pode servir de reflexão e suscitar estratégias similares em outros municípios. O destaque para a cidade de Curitiba foi o cálculo de cardápios diversificados aos escolares com necessidades especiais, que têm direito a uma alimentação adequada às suas particularidades $^{1,2,23}$. Ressalta-se Florianópolis por apresentar alimentos da cultura local semanalmente no cardápio. Além da contribuição biológica, a alimentação é um ato simbólico em que são consagradas relações afetivas e repassados valores culturais $^{24}$ que devem ser reforçados pelo PNAE.

Na subdimensão "Monitoramento alimentar e nutricional", foi possível perceber como a atuação intersetorial teve influência positiva, já que Curitiba disponibilizava dados antropométricos anuais dos escolares devido à parceria estabelecida com o setor saúde. Ressalta-se que a falta de recursos humanos capacitados é frequentemente referida como empecilho para a realização de ações de monitoramento ${ }^{4}$. A situação evidenciada nas três capitais corrobora dados da região Nordeste, em que $43 \%$ dos nutricionistas relataram nunca realizar o monitoramento nutricional dos escolares ${ }^{15}$. 
Na subdimensão "Atuação pedagógica para a alimentação saudável", observou-se semelhança com o estudo realizado em municípios nordestinos, em 2012. Neste, 33\% dos nutricionistas entrevistados realizavam frequentemente atividades de promoção da alimentação saudável e educação nutricional ${ }^{15}$, assim como em uma das capitais aqui observadas (Florianópolis). A ausência da inserção do tema alimentação saudável no currículo da rede de ensino fundamental, de forma atual e efetiva, também é um dado preocupante. Apenas a oferta de uma alimentação adequada não basta para a efetivação dos objetivos do programa. Tratando-se de desenvolvimento de hábitos alimentares saudáveis, a prática deve ser suportada pela teoria para melhor assimilação do conteúdo ${ }^{23}$. Como as crianças encontram-se em fase de pleno desenvolvimento cognitivo, ações educativas no campo da alimentação, adequadas aos distintos contextos, mostram-se necessárias ${ }^{25}$.

No quesito estudos avaliativos, ainda que tenham sido identificados muitos trabalhos que avaliam algum aspecto do PNAE, poucos estabeleceram previamente à coleta dos dados que peso seus resultados teriam na avaliação final. Além disso, foram identificados poucos estudos propondo um julgamento propriamente dito como resultado, sendo encontrados com frequência diagnósticos e descrições dos aspectos do PNAE. Dentre as investigações que se dedicaram a estabelecer uma proposta de julgamento sistemática para o programa, utilizando-se para tal dimensões, indicadores e seus desdobramentos, duas apresentam maiores semelhanças metodológicas com o modelo utilizado no presente estudo, incluindo componentes da gestão municipal do $\mathrm{PNAE}^{7,8}$. Uma dessas metodologias foi desenvolvida em 2009 com três dimensões de análise gestão; participação e controle social; eficiência alimentar e nutricional -, e um total de 28 indicadores $^{7}$. Metodologia posterior, desenvolvida em 2012, elencou seis dimensões - gestão; participação e controle social; desenvolvimento local; promoção da alimentação saudável; qualificação dos atores e opinião dos atores -, que totalizaram 88 indicadores $^{8}$. Embora os trabalhos identificados tenham auxiliado de maneira importante na proposição e discussão do presente modelo avaliativo, até o momento não foram encontrados nas bases de dados investigadas resultados de estudos que aplicaram as metodologias supracitadas. Esses achados justificam o presente trabalho, uma vez que apontam para a premência desses instrumentos diante do atual desenho de programas sociais como o PNAE.

Tendo em vista que a avaliação deve constituir-se importante instrumento para o município, devendo possibilitar a avaliação periódica da situação e a identificação de fatores responsáveis pelos resultados ${ }^{6}$, em 2013 foi realizada oficina coletiva para apresentação e discussão dos resultados com as capitais envolvidas. A oficina caracterizou-se pela troca de experiências, revisão de muitas das ações e pactuação de melhorias conforme as fragilidades encontradas. Um dos propósitos da oficina foi aproximar o modelo avaliativo dos atores sociais responsáveis pela proposição e pelo acompanhamento das ações no nível local. Como o processo avaliativo é dinâmico, indicadores podem ser ajustados ou adicionados ao modelo, que deve ser empregado para qualificar a atuação da gestão. Ressalta-se que a institucionalização da avaliação requer a parceria de distintos atores, dentre os quais estão os nutricionistas e outros profissionais da saúde, profissionais da educação, agricultura, demais membros da comunidade escolar, órgãos governamentais e sociedade civil.

\section{CONSIDERAÇÕES FINAIS}

Este artigo avaliou a gestão municipal do PNAE nas três capitais do Sul do Brasil por meio de modelo avaliativo desenvolvido e testado em estudo anterior ${ }^{9}$. O modelo assegura a avaliação de pontos considerados chaves para a adequada execução do programa no nível municipal, e que, por conseguinte, devem ser priorizados pela entidade executora local. 
As referências teóricas centrais do modelo foram orientadas pelos princípios e diretrizes do PNAE, os quais estão em consonância com os aspectos propostos pela Política Nacional de Segurança Alimentar e Nutricional e dispõem sobre as atribuições institucionais para execução do Programa ${ }^{9,13}$.

Quantos às capitais investigadas, apesar de apresentarem semelhante situação socioeconômica, possuem características geopolíticas e de gestão do PNAE diferentes. Em termos de índices de desenvolvimento da educação e humano, podem ser ressaltadas diante de outras cidades brasileiras. A área, a densidade populacional e o público atendido pelo programa são bem distintos, o que demanda diferentes decisões de gestão diante de programas públicos como o PNAE.

A avaliação resultou em classificação regular para Florianópolis e Curitiba e ruim para Porto Alegre, panorama ainda distante do ideal. Apesar disso, cada capital apresentou particularidades de destaque que podem servir de exemplo e estimular melhorias por parte das ações de gestão, subsidiando outros municípios. Embora não fosse objetivo do estudo, evidenciaram-se tendências conforme as modalidades de execução do PNAE, as quais se mostraram bastante diversificadas, demandando aprofundamento. No quesito prática avaliativa, destaca-se a preocupação ainda presente com a insuficiência de dados nacionais, sistematizados e de livre acesso acerca da implementação do programa.

A realidade observada em campo demanda reflexões e revisões, estando bastante distanciada dos pressupostos teóricos propostos pelo PNAE. Nesse sentido, algumas questões podem vir à tona: será o modelo tão exigente a ponto dos municípios não conseguirem bons resultados? Ou seriam os gestores locais insuficientemente qualificados para a operacionalização do programa? Ou ainda, será que a proposta teórica do PNAE está muito além das possibilidades reais de execução?

Estes questionamentos devem ser pensados a partir da história recente das políticas sociais brasileiras. Mesmo o PNAE datando da década de 1950, foi somente a partir da década de 1990 que conceitos como descentralização e participação social passaram a ser inseridos na sua lógica de funcionamento. A própria discussão sobre segurança alimentar e nutricional como política é bastante recente e posterior ao surgimento do programa de alimentação escolar, que foi sendo redesenhado ao longo dos seus sessenta anos de existência.

Sendo assim, todo o arcabouço proposto para as políticas e programas de segurança alimentar e nutricional, como o PNAE, pode ainda ser considerado um desafio e um modo novo de planejar e realizar ações. Nessa perspectiva, é possível presumir que, dentro do contexto em que se desenvolvem, alguns dos resultados encontrados são compreensíveis e, até mesmo, esperados. Todavia, isso não invalida a premente necessidade de revisão e qualificação de muitas das ações. Conforme referido, o modelo utiliza, predominantemente, as referências legais do PNAE, o que reforça a necessidade da viabilização de condições adequadas para que essas premissas se concretizem.

\section{COLABORADORES}

CG GABRIEL colaborou na concepção da pesquisa, na coleta, na análise e interpretação dos resultados e na redação do manuscrito. G GOULART colaborou na análise e na interpretação dos resultados e na redação do manuscrito. MCM CALVO colaborou na concepção da pesquisa, na estruturação e na revisão crítica do manuscrito.

\section{REFERÊ NCIAS}

1. Brasil. Presidência da República. Lei $n^{\circ} 11.947$, de 16 de junho de 2009. Dispõe sobre o atendimento da alimentação escolar e do Programa Dinheiro Direto na Escola aos alunos da educação básica. Diário Oficial da União. 2009; 17 jun.

2. Brasil. Ministério da Educação. Fundo Nacional de Desenvolvimento da Educação. Resolução $n^{\circ} 26$, de 17 de junho de 2013. Brasília: MEC; 2013 [aces- 
so 2015 jan 15]. Disponível em: http://www.fnde. gov.br/fnde/legislacao/resolucoes/item/4620-resolu \% C 3\%A7\% C 3\%A3o-cd-fnde-n \% C 2\%BA-26de-17-de-junho-de-2013

3. Gabriel CG, Machado MS, Schmitz BAS, Corso ACT, Caldeira GV, Vasconcelos FAG. Conselhos Municipais de Alimentação Escolar em Santa Catarina: caracterização e perfil de atuação. Ciênc Saúde Colet. 2013; 18(4):971-8. http://dx.doi.org/10.15 90/S1413-81232013000400009

4. Chaves L, Santana TCM, Gabriel CG, Vasconcelos FAG. Reflexões sobre a atuação do nutricionista no Programa Nacional de Alimentação Escolar no Brasil. Ciênc Saúde Colet. 2013; 18(4):917-26. http://dx. doi.org/10.1590/S1413-81232013000 400003

5. Saraiva EB, Silva APF, Sousa AA, Cerqueira GF, Chagas CMS, Toral N. Panorama da compra de alimentos da agricultura familiar para o Programa Nacional de Alimentação Escolar. Ciênc Saúde Colet. 2013; 18(4):927-35. http://dx.doi.org/10.15 90/S1413-81232013000400004

6. Santos LMP, Santos MC, Santana LAA, Henrique FCS, Mozza RPD, Santos LAS, et al. Avaliação de políticas públicas de segurança alimentar e combate à fome no período 1995-2002. 4 - Programa Nacional de Alimentação Escolar. Cad Saúde Pública. 2007; 23(11):2681-93. http://dx.doi.org/10.1590/S 0102-311X2007001100016

7. Silva AV. Avaliação do Programa Nacional de Alimentação Escolar em âmbito municipal: subsídios para o desenvolvimento de uma metodologia [mestrado]. Bahia: Universidade Federal da Bahia; 2009.

8. Carvalho CMP. Proposta de avaliação do Programa Nacional de Alimentação Escolar para municípios do estado do Rio de Janeiro [mestrado]. Rio de Janeiro: Universidade Federal do Rio de Janeiro; 2012.

9. Gabriel CG, Calvo MCM, Ostermann RM, Vasconcelos FAG. Proposta e teste de aplicabilidade de modelo para avaliação da gestão municipal do Programa Nacional de Alimentação Escolar. Cad Saúde Pública. 2014; 30(8):1731-44. http://dx.doi. org/10.1590/0102-311X00033913

10. Belik W, Chaim NA. O Programa Nacional de Alimentação Escolar e a gestão municipal: eficiência administrativa, controle social e desenvolvimento local. Rev Nutr. 2009; 22(5):595-607. http://dx.doi. org/10.1590/S1415-52732009000500001

11. Gabriel CG, Costa LCF, Calvo MCM, Vasconcelos FAG. Planejamento de cardápios para alimentação escolar de alunos de escolas públicas municipais: reflexão e ilustração deste processo em duas capitais brasileiras. Rev Nutr. 2012; 25(3):363-72. http:// dx.doi.org/10.1590/S1415-52732012000300006
12. Pipitone MAP, Ometto AMH, Silva, MV, Sturion GL, Furtuoso MCO, Oetterer M. Atuação dos conselhos municipais de alimentação escolar na gestão do Programa Nacional de Alimentação Escolar. Rev Nutr. 2003; 16(2):143-54. http://dx.doi.org/10.15 90/S1415-52732003000200001

13. Gabriel CG, Calvo MCM, Ostermann RM, Vasconcelos FAG. Avaliação da gestão municipal do Programa Nacional de Alimentação Escolar nos maiores municípios de Santa Catarina. Cad Saúde Pública. 2014; 30(9):2017-23. http://dx.doi.org/ 10.1590/0102-311XER00112813

14. Federação Nacional dos Nutricionistas. Tabela de honorários. Porto Alegre: Federação Nacional dos Nutricionistas; 2011 [acesso 2015 jan 15]. Disponível em: http://www.sindinutri-es.org.br/ noticias/nacional/tabela-de-honorarios-2011

15. Mello AL, Vidal JPO, Sampaio LR, Santos LAS, Freitas MCS, Fontes GAV. Perfil do nutricionista do Programa Nacional de Alimentação Escolar na região Nordeste do Brasil. Rev Nutr. 2012; 25(1):119-32. http://dx.doi.org/10.1590/S1415-5273201200 0100011

16. Brasil. Presidência da República. Decreto-Lei $n^{\circ}$ 5.452 , de $1^{\circ}$ de maio de 1943 . Aprova a consolidação das leis do trabalho. Diário Oficial da União. 1943; 9 ago, p.11937.

17. Cardoso RCV, Góes JAW, Almeida RCC, Guimarães AG, Barreto DL, Silva AS, et al. Programa Nacional de Alimentação Escolar: há segurança na produção de alimentos em escolas de Salvador (Bahia)? Rev Nutr. 2010; 23(5):801-11. http://dx.doi.org/10.15 90/S1415-52732010000500010

18. Teo CRPA, Corrêa EN, Gallina LS, Fransozi C. Programa Nacional de Alimentação Escolar: adesão, aceitação e condições de distribuição de alimentação na escola Nutrire. Rev Soc Bras Aliment Nutr. 2009; 34(3):165-85.

19. Goulart G, Nascimento MELO, Sousa AA, Kuntz MGF, Alencar MLA. Construção de um guia ilustrativo de medidas caseiras padronizadas para o porcionamento de componentes do cardápio do SND/ HU/UFSC. Nutr Pauta. 2010; 100:58-62.

20. Sturion GL, Silva MV, Ometto AMH, Furtuoso MCO, Pipitone MAP. Fatores condicionantes da adesão dos alunos ao Programa de Alimentação Escolar no Brasil. Rev Nutr. 2005; 18(2):167-81. http://dx. doi.org/10.1590/S1415-52732005000200001

21. Gabriel CG, Santos MV, Vasconcelos FAG, Milanez GHG, Hulse SB. Cantinas escolares de Florianópolis: existência e produtos comercializados após a instituição da Lei de Regulamentação. Rev Nutr. 2010; 23(2):191-9. http://dx.doi.org/10.1590/S14 15-52732010000200002 
22. Brasil. Ministério da Saúde. Regulamentação da comercialização de alimentos em escolas no Brasil: experiências estaduais e municipais. Brasília: Ministério da Saúde; 2007.

23. Cunha E, Sousa AA, Machado NMV. A alimentação orgânica e as ações educativas na escola: diagnóstico para a educação em saúde e nutrição. Ciênc Saúde Colet. 2010; 15(1):39-49. http://dx.doi.org/ 10.1590/S1413-81232010000100009

24. Assao TY. Alimentação escolar: percepção dos atores sociais de escolas de um município da região metropolitana de São Paulo [doutorado]. São Paulo: Universidade de São Paulo; 2012.

25. Gaglianone CP, Tadei JAAC, Colugnati FAB. Educação nutricional no ensino público fundamental em São Paulo, Brasil: projeto redução dos riscos de adoecer e morrer na maturidade. Rev Nutr. 2006; 19(3):309-20. http://dx.doi.org/10.1590/s1415-52 732006000300002
Recebido: abril 14, 2015

Versão final: julho 13, 2015 Aprovado: agosto 3, 2015 